\title{
COMPARAÇÃO DOS PRINCIPIOS TECNOLÓGICOS DO PROCESSAMENTO DE SUCO DE MAÇÃ AOS DOS DE PÊRA
}

\section{TECHNOLOGICAL PRINCIPLES OF APPLE JUICE PROCESSING AS COMPARED TO THOSE OF PEAR}

\author{
Talita Pereira Lopes ${ }^{1}$, Suelen Avila ${ }^{1}$, Acácio Antonio Ferreira Zielinski ${ }^{1}$, Alessandro Nogueira ${ }^{1}$, \\ Gilvan Wosiacki ${ }^{1}$ \\ ${ }^{1}$ Universidade Estadual de Ponta Grossa - UEPG - Ponta Grossa - Brasil wosiacki@ uol.com.br
}

\begin{abstract}
Resumo
A cultura de pereira apresenta potencial de expansão na Região Sul do Brasil podendo aproveitar parte da infraestrutura tecnológica e de armazenamento já instalada para a cultura da macieira, desde a pesquisa de melhoramento genético com técnicas de manejo mais atualizadas e econômicas. $O$ país, considerado um grande produtor de frutas, pode dentro de algum tempo suprir a demanda com peras de qualidade como aconteceu com a pomicultura nas últimas três décadas. $O$ objetivo deste artigo trata da avaliação das possibilidades de serem usados os caminhos tecnológicos da maçã para a pêra com tempo hábil para que possa ser incrementada a sua produção e ao mesmo tempo possa ser planejado o seu processamento com produtos nobres. Raras unidades industriais são vinculadas ao processamento de suco, porém safras com muita produção bem como os subprodutos desqualificados para o comércio no varejo faz com que se viabilize o processamento de produtos nobres, até mesmo como base para outras bebidas inovadoras. Para tanto, amostra de pêras comerciais são descritas quanto às suas singularidades desde aspectos botânicos até de acabamento de produtos, mantendo a maçã como referencial científico $e$ tecnológico e com isto se procura verificar se os equipamentos utilizados no processamento da maçã são adequados para a pêra. Os rendimentos gravimétricos comparados do suco de pêra e de maçã foram úteis para indicar a afinidade de cada matéria prima sendo que os resultados obtidos com a despolpadeira e pela tecnologia enzimática foram os quantitativamente melhores enquanto o convencional apresentou o mais baixo.
\end{abstract}

Palavras-chave: pomáceas, operações de processamento, produtos.

\section{Introdução}

As frutíferas provenientes da região entre Cáucaso e leste da China foram às primeiras domesticadas e dentre as espécies mais antigas estão à macieira, videira, cítricos, figueira e pereira (SAWAZAKI et al., 2008).

O cultivo da primeira mobilizou a infraestrutura agronômica da Região Sul e foi implantado sob tecnologia moderna tendo atingido a maturidade em 2005, suprindo o mercado 
interno com 1.000.000 de toneladas métricas após 30 anos de uma atividade programada. A maçã tem repercussão na medicina caseira por que apresenta substâncias antiinflamatórias e cicatrizantes, sendo depurativa, sedativa, adstringente além de exercer reguladora hormonal (CLAUDINO, 2009). As variedades que apresentaram maior produção por área plantada com menor custo de produção foram selecionadas dentre as agronomicamente viáveis e compreendem a Fuji e a Gala, tendo sido reduzido o plantio da Golden delicious dada em função de sua aparência prejudicada com russeting intenso; com a diminuição da oferta a demanda aumentou e esta variedade voltou ao mercado doméstico. Cerca de $20 \%$ da produção é recuperado da fração desclassificada e transformada em base de fermentação para beneficiamento de sidra e outras bebidas frisantes e $10 \%$ se constituem no principal resíduo da agroindústria de maçã. As bem sucedidas exportações, a cada ano melhorando seu nível no comércio exterior, sugerem um upgrade na tecnologia de obtenção de suco concentrado de maçã, com um rendimento de até 6,0 a $6,2 \mathrm{~kg}$ de fruta por $1 \mathrm{~kg}$ de suco concentrado a $72^{\circ}$ Brix o que representa um ganho superior a $90 \%$ com uma capacidade maior do que 7 a $10 \mathrm{t}$ (ISSENHUT e SCHNEIDER, 2008; MAIER, 2010).

O cultivo da última, a pêra, está ainda incipiente no país uma vez que atende apenas $20 \%$ da demanda de 150.000 toneladas anuais, o que explica o elevado porte de sua importação. As variedades derivadas das espécies Pyrus serotina R. e Pyrus communis L., de origem asiática ocidental, respectivamente, atendem a preferência do consumidor doméstico brasileiro com quantidade e qualidade dependendo de importações da Argentina, Chile, Estados Unidos, Uruguai e Portugal, prática esta que disponibiliza a oferta durante o ano todo (FIORAVANÇO, 2007).

Os Institutos de Pesquisa nos estados do Sul dão continuidade aos seus projetos que contemplam esta fruta voltando-se para a rusticidade de planta e qualidade das frutas, por meio de ferramentas de nanobiotecnologia (SAWAZAKI et al., 2008). A pêra tem, a exemplo da pomácea anterior, muitos itens recomendados na medicina do lar, contendo $80 \%$ de água, $13 \%$ de carboidratos, $0,5 \%$ de sais minerais, e as fibras solúveis e insolúveis, vitaminas do complexo B e vitamina C. Muito importante na dieta de diabéticos, por seu baixo valor glicêmico, também tem a capacidade de manter estáveis os níveis de colesterol por seu elevado conteúdo de fibras. Recomendada para nefríticos, convalescentes e hipertensos, é laxante e utilizada em enfermidades intestinais e renais, capaz de estimular as funções cerebrais acalmando a ansiedade e contém atividade mucolíticas (CLAUDINO, 2009).

Peras, de um ponto de vista global, são direcionadas ao processamento de suco muito raramente, e isto só acontece quando o volume da safra for muito superior à média anual, porém ao ser observada a sua composição química, em especial o seu conteúdo em frutose e a possibilidade de agregação de qualidade a diferentes tipos de sucos, torna-se uma matéria prima especial merecedora de pesquisa e desenvolvimento (NIKETIC-ALEKSIC et al., 1989). Na modernidade a 
cultura da pêra é conduzida de forma alternativa, mas em nível técnico está sendo buscada uma identidade nacional de pêra visando à exploração comercial. Com a finalidade de contribuir com este desenvolvimento, desde o agronômico ao tecnológico, do social ao econômico, os objetivos deste artigo tratam de sua avaliação da capacidade de serem usados os mesmos caminhos tecnológicos com tempo hábil para que possa ser incrementada a sua produção e ao mesmo tempo possa ser planejado o seu processamento com produtos nobres.

\section{Material e Métodos}

\section{Material}

Amostras de 40 kg de pêra da variedade Packham's Triumph (safra 2009/2010) e de maçã da variedade Gala (safra 2009/2010), constituíram-se nos sujeitos do conjunto de experimentos. As preparações enzimáticas para despectinização (Pectinex ${ }^{\circledR}$ 100L Plus, Pectinex ${ }^{\circledR}$ UltraMASH), de fabricação da Novozymes foram doadas pelo seu representante LNF de Bento Gonçalves - RS. Produtos químicos foram de pureza P.A.

\section{Métodos}

\section{Processos}

As matérias-primas em estádio de maturação adequadas foram selecionadas, lavadas e sanitizadas com hipoclorito de sódio $\left(100 \mathrm{mg} \mathrm{L}^{-1}\right)$,e em seguida processadas de acordo com uma das seguintes operações (Quadro 1):

Quadro 1 - Diferentes operações de extração de sucos de maçã e de pêra

\begin{tabular}{|l|l|}
\hline OEX1 & Operação de Extração 1 - Tecnologia Mecânica \\
\hline OEX2 & Operação de Extração 2 - Despolpadeira \\
\hline OEX3 & Operação de Extração 3 - Multiprocessador de Alimentos \\
\hline OEX4 & Operação de Extração 4 - Tecnologia Enzimática \\
\hline
\end{tabular}

Na operação OEX1 as frutas foram fragmentadas em moinho de facas (Metvisa, 180 $\mathrm{kg} \mathrm{h}^{-1}$ ) com tamanhos médios de 4,2 cm de comprimento e $0,3 \mathrm{~cm}$ de espessura, sendo que a massa ralada acondicionada em pacotes de plástico poroso que, superpostos, foram submetidos a uma pressão de $3 \mathrm{~kg} \mathrm{~cm}^{-2}$ durante 3 vezes por 5 minutos (Prensa hidráulica Potente Brasil, $15 \mathrm{~kg} . \mathrm{cm}^{-2}$ ). Na OEX2 as frutas foram despolpadas em equipamento automático (Linha Nobre DES-60, $100 \mathrm{~kg} \mathrm{~h}^{-1}$ ) equipado com peneira de furos de 2,0 mm de diâmetro. OEX3 as amostras foram processadas em multiprocessador de alimentos (Walita, RI1861) equipado com faca tipo ralador sendo o suco 
separado no equipamento por força centrifuga. $\mathrm{Na} \mathrm{OEX} 4$ as frutas foram moídas em liquidificador industrial e a massa liquidificada foi colocada em becker e incubada em estufa tipo shaker (Marconi) sob agitação de $150 \mathrm{rpm}$ a $45{ }^{\circ} \mathrm{C}$ para equilíbrio da temperatura de reação, e quando esta foi estabilizada foram adicionados $50-120 \mathrm{~mL} \mathrm{ton}^{-1}$ da preparação enzimática Pectinex ${ }^{\circledR}$ UltraMASH conforme as especificações do fabricante mantendo-se incubadas então por 60 min. Após, as amostras foram submetidas a um aquecimento em banho-maria fervente em cápsulas hermeticamente fechada por três minutos para desnaturação das enzimas, sendo retiradas por força centrífuga (800 g x 20min) em nível de laboratório (Figura 1).

Os sucos extraídos dos diferentes processos, passaram pelo processo de despectinização na adição de Pectinex ${ }^{\circledR} 100 \mathrm{~L}\left(3,0 \mathrm{~mL} \mathrm{hL}^{-1}\right)$ a quente $\left(45^{\circ} \mathrm{C}\right.$ por $\left.60 \mathrm{~min}\right)$. Após sedimentação foram trasfegados e filtrados em papel em condições normais de temperatura e pressão (CNTP). Os sucos passaram pelo processo de colagem com gelatina $\left(3,0 \mathrm{~g} \mathrm{hL}^{-1}\right)$ e bentonite $\left(40 \mathrm{~g} \mathrm{hL}^{-1}\right)$ para remoção dos compostos químicos indesejáveis com benefícios à aparência final do produto (FERTONANI et al., 2006; NOGUEIRA et al., 2003).

Figura 1 - Fluxograma de suco clarificado de maçã e pêra com quatro diferentes operações unitárias

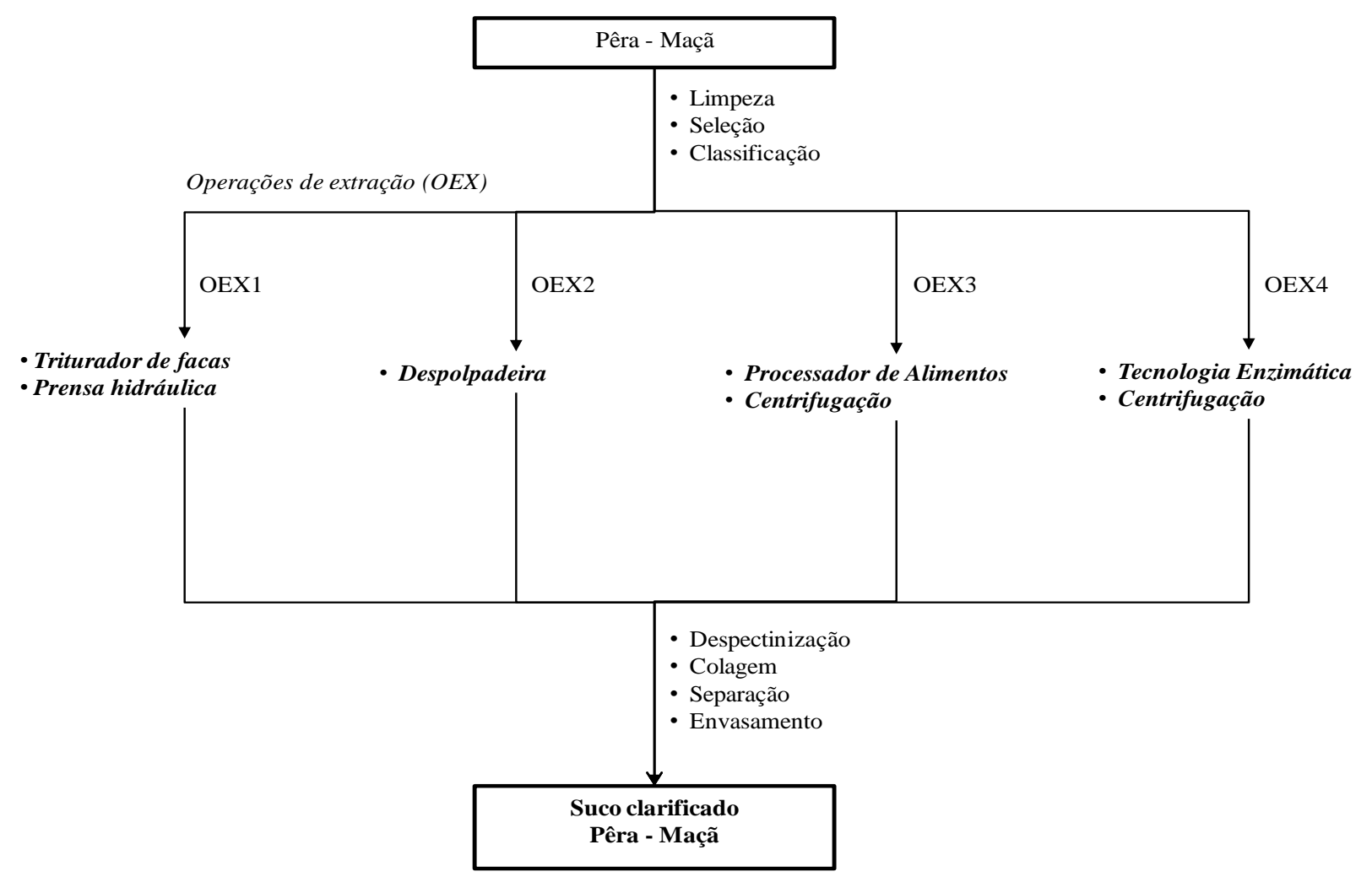




\section{Determinação do Rendimento}

O rendimento de extração, como a razão entre o volume de suco extraído por massa de matéria-prima $\left(\mathrm{L} \mathrm{Kg}^{-1}\right)$, foi determinado por método gravimétrico

\section{Análises Químicas}

Os sólidos solúveis totais foram determinados por leitura analítica em refratômetro de bancada, sendo expresso em ${ }^{\circ}$ Brix (IAL, 2005). A intensidade de cor foi determinada em espectrofotômetro UV-VIS (Shimadzu, UV mini 1240) pela soma das absorbâncias de 440ๆm e 520 $\eta \mathrm{m}$ que correspondem aos cromóforos relativos aos polifenóis e pigmentos antocianínicos, respectivamente (TANNER e BRUNNER; 1985).

A acidez total titulável foi determinada de acordo com os métodos do IAL (2005) por titulometria com solução $0,1 \mathrm{~N}$ de $\mathrm{NaOH}$ fatorada com biftalato ácido de potássio sendo calculada para ser expressa em massa de ácido málico por $100 \mathrm{~mL}$ de suco $\left(\mathrm{g} .100 \mathrm{~mL}^{-1}\right)$.

Os compostos fenólicos totais foram quantificados através de modificações da análise colorimétrica de Folin-Ciocalteu descrita por Singleton e Rossi (1965). Os resultados foram expressos em mg L $\mathrm{m}^{-1}$ de fenólicos totais, utilizando catequina (SIGMA, C-1251) como padrão (200 $\left.\mu \mathrm{g} \mathrm{mL}{ }^{-1}\right)$

\section{Determinação da Atividade antioxidante}

A determinação da atividade antioxidante, foi utilizado o método de FRAP, descrito por Benzie e Strain (1996) e Pulido et al. (2000). Como padrão, foi utilizado o reativo ácido 6-hidroxi2,5,7,8-tetrametilchroman-2-carboxílico (TROLOX - Flucka Chemicals Suisse - Cód. 56510) em concentração apropriada, com a diluição realizada para cada amostra: $3 \mathrm{~mL}$ do reagente FRAP e $100 \mu \mathrm{L}$ do padrão ou amostra foram adicionados em tubo de ensaio e a leitura da absorbância foi realizada a $593 \mathrm{\eta m}$, utilizando o reagente FRAP como branco (L1). O resultado foi expresso como $\mu \mathrm{M} \mathrm{mL} L^{-1}$.

\section{Análise Estatística}

Os resultados dos procedimentos experimentais foram analisados mediante análise de variância (ANOVA), com 95\% de confiabilidade e, caso existam diferenças, estas foram discriminadas pelo teste diferencial de TUKEY, a 5\% de probabilidade pelo software estatístico STATISTICA 7.0 for Windows (Statsoft, INC.) 


\section{Resultados e Discussões}

\section{Processos}

OEX1 o suco foi extraído dos fragmentos com $4,2 \mathrm{~cm}$ de comprimento e $0,3 \mathrm{~cm}$ de espessura discretos das frutas por força mecânica em prensa vertical (escala de laboratório) com pressão de $3 \mathrm{~kg} \mathrm{~cm}^{-2}$ por $5 \mathrm{~min}$, por 3 vezes. Foi separado o suco do bagaço por tamisação em sacos plásticos com porosidade e os fragmentos da própria matéria prima, resfriada em geladeira ou caminhos aquático, durante o processo foram elementos filtrantes para o suco surgiu tornando-se mais límpido e com padrão preconizado pelo mercado consumidor internacional (HURLER e WEY, 1984). Trata-se do processo mais convencional e algumas poucas modificações são agregadas como resultado de pesquisas e redirecionamento da demanda mercadológica, ultimamente, de prensas em formas de esteiras e de centrífugas de grande capacidade e elevado porte (BIRUS, 2001). Porém, como a pêra é uma fruta com menor resistência que acaba se desmanchando na operação de prensagem, assim sua aptidão é menor nos procedimentos correntemente aplicados no setor agroindustrial brasileiro (HERRMANN, 2001).

Na OEX2 foi utilizado despolpadeira como vantagem, além de demandar um único equipamento, foi preconizar um alto rendimento de extração. $\mathrm{O}$ equipamento, que pode ser regulado para diferentes frutas, remove as sementes e os materiais celulósicos da massa liquidificada em moinho de facas e o suco é recebido em recipientes, enquanto que remanesce no interior o bagaço e grande parte de polpa com perdas que diminuem à medida que aumenta a quantidade de matériaprima. Elevada quantidade de resíduo se deve à necessidade de calibrar a máquina adaptando-a para cada matéria-prima, seja por tipo de fruta ou por condições anatomo-fisiológicas. Tem como desvantagem a incorporação de oxigênio que conduz a um produto de maior intensidade de cor o que reflete da oxidação tanto enzimática quanto não enzimática da polpa aerada (HAMINIUK et al., 2005). O produto obtido é na verdade polpa da fruta, muito mais viscosa que o suco propriamente dito, dificultando também nas operações de acabamento para obtenção de suco. Embora o equipamento admita um único operador, isto conduz a um gargalo do processo que é superado pelo atendimento com menor escala ou maior quantidade de recursos técnicos. O scale up deste equipamento aumenta a distância entre a produção de suco e a massa residual no seu interior, minimizando o prejuízo intrínseco do equipamento (BIRUS, 2001).

A OEX3 o ralador se constitui num moinho de facas que desestrutura a matéria prima e o resultado é uma massa amorfa que rapidamente se escurece, com perdas nutricionais importantes (HAMINIUK et al., 2005). A centrífuga, de forma geral, separa pelo aumento da força gravitacional os sólidos dos líquidos, com uma vasta possibilidade de situações considerando-se os estados 
físicos da matéria. A junção das duas máquinas constitui um equipamento suis generis que, ao mesmo tempo em que rala a matéria prima separa os sólidos (bagaços) dos líquidos (sucos). O equipamento contém um raspador ou ralo que simula um moinho de facas de alta potência sendo que os fragmentos de polpa que passam pelos orifícios do ralo são recolhidos em um orifício, enquanto que o material que não passa pelos crivos é retirado do equipamento pela lateral sendo recebido em um recipiente para descarte. A operação de extração está restrita à fragmentação física da matéria prima e extração do suco livre por força centrífuga. O suco incorpora grande quantidade de ar (oxida), o que é percebido pela espuma formada. O bagaço sai úmido, ou seja, ainda contém grande quantidade de suco. O suco obtido contém pedaços da fruta, que são contabilizados no rendimento, isto dificulta as operações posteriores de despectinização, clarificação e filtração do produto.

$\mathrm{Na}$ OEX4 geralmente as enzimas são utilizadas para aumentar a velocidade dos processos de extração e as condições de incubação podem ser maximizadas e também otimizadas, o que demanda estudos com apoio de planejamento de experimentos para determinar as condições ótimas de reação. Modernamente, pêras e maçãs são moídas e o mosto é tratado com enzimas à razão de 40-80 mL ton ${ }^{-1}$ de Pectinex ${ }^{\circledR}$ YieldMASH ou 50-120 mL ton ${ }^{-1}$ de Pectinex ${ }^{\circledR}$ UltraMASH e então incubado de 15 a $27^{\circ} \mathrm{C}$ sem agitação por 30 a 120 min e depois deste tempo submetidas ao processo convencional de prensagem (NOGUEIRA et al., 2005). A extração do suco presente no mosto, altamente desestruturado em termos físicos em liquidificador com alta rotação e químicos, por enzimas (STUTZ, 1996), é feita por força centrífuga que separa a parte líquida (sobrenadante, suco) da parte sólida (precipitado ou bagaço). Esta pode ser considerada como subproduto para uso como fertilização de solo ou como ração animal, mas também considerado como resíduo quando se considera o custo negativo do tratamento. No caso de tecnologia enzimática esta dialética desvanece dada a total desestruturação das fibras solúveis e insolúveis e se resume à consideração como resíduo (MAIER, 2010; STUTZ, 1996).

\section{Rendimento de suco}

Os rendimentos obtidos com o processamento das pomáceas são mostrados na Tabela 1.

A moagem deve levar a um produto discreto e uniforme, dotado de resistência estrutural, mas permeável ao fluido intracelular possibilitando que a aplicação de força vertical ao sistema extraia o suco que permeia por todas as direções usando a fração sólida como um coadjuvante de filtração. A fim de otimizado, o processo, a matéria prima, fria, deve ser usada sendo fragmentada por um moinho de facas capaz de cortar nas três dimensões e de liberar minúsculos cubos com 0,5 a $1 \mathrm{~cm}^{3}$ (HURLEY e WEY, 1984), exceto no caso de uso de enzimas. 
As matérias-primas que foram utilizadas nos experimentos eram todas de mesmo lote visando eliminar um fator de dispersão, na tentativa de diminuir o grau de heterogeneidade da amostra, embora os fenômenos interferentes sejam muito diversos. Não se pretende aqui, todavia, supor que estas amostras sejam representativas da produção brasileira, nem da região de cultivo, mas sim discriminar aquelas singularidades que possam servir como um padrão passível de ser reconhecido pela análise de componentes principais e, desta forma, obter modelos que garantam a qualidade de uma partida discreta de frutas pomáceas.

Quanto ao rendimento do suco de frutas, na modernidade o mais simples e prático que está sendo considerado se apresenta como a quantidade de suco extraído da matéria-prima, em kg por $100 \mathrm{~kg}^{-1}$ (p/p), possível de ser usado rotineiramente na linha de produção (BIRUS, 2001), mas uma simples inspeção em chão de fábrica indica que há uma quantidade de suco desconsiderada presente no bagaço. As duas abordagens, a simples extração do suco, e a recuperação do resíduo industrial, por rinsagem e nova extração, podem aumentar o rendimento de forma significante se for medida em sólidos solúveis totais (DEELEN e STEINBUCH, 1986). Na prática amparada pela legislação alemã (maior comprador mundial de suco de maçã) pertinente, prefere-se determinar quantos kg de maçã são necessários para fabricar $1 \mathrm{~kg}$ de suco concentrado a 72\% (MAIER, 2010) podendo chegar de 6 a 8 kg de maçã. Uma alternativa é a proposta original de Binnig e Possmann (1993), usando quatro componentes que se obtém com facilidade e aplicando a fórmula a seguir:

$$
\begin{gathered}
\text { Rendimento } \%(\mathrm{~m} / \mathrm{m})=100 *(S S B-S I S) /(S I B-S S S) \\
\text { SS }=\text { Sólidos solúveis, B = Bagaço, } \mathrm{SI}=\text { Sólidos insolúveis, } \mathrm{S}=\text { Suco }
\end{gathered}
$$

Ao ser comparado, o rendimento no processamento de suco de pêra a operação OEX2 (76,24\%) está longe da média encontrada no conjunto (64,78\%) e frente aos demais ensaios, indica que se trata da melhor forma de processamento. Pode ser observado que a OEX2 se equivale a OEX4 em termos numéricos, enquanto a OEX1 e OEX3 se apresentam como os de menor rendimento, com menor adequação à pêra do que à maçã. Do ponto de vista quantitativo, portanto, as pêras são mais aptas as operações OEX2 e OEX4 e menos aos demais ao passo que a maçã é em todos os casos, apta, porém respeitando a mesma ordem, crescente: OEX1 < OEX3 < OEX4< OEX2.

Os valores que se referem ao processamento de suco de maçã sem adição de enzimas de maceração foi determinada uma média de $70,14 \%$, são compatíveis com os da literatura que apresentam valores de 67 a $70 \%$, assim como a OEX4 se apresenta com valor mais homogêneo $(69,57 \%)$ comparado ao relatado por Niketic-Aleksic et al. (1989) de 38\% a $72 \%$. 
Nesta pesquisa a opção foi por duas etapas irreversíveis do fluxograma, a moagem e a extração, que juntas constituem uma fase comum aos procedimentos tecnológicos. A razão entre os rendimentos da pêra pelos da maçã $\left(\mathrm{Rm}=100 * \mathrm{R}_{\mathrm{P}} / \mathrm{R}_{\mathrm{M}}\right)$, como apresentada a Tabela 1 , caracteriza a pêra como apta aos procedimentos tecnológicos apropriados para a maçã, com um grau de similaridade que ultrapassa os $100 \%$, no caso da OEX2 e OEX4 caindo a $89 \%$ e $73 \%$ nos casos da OEX3 e da OEX1. Como corolário, a liberação do bagaço apresenta valores complementares, pois com o suco deveria ser considerado o quanto supra para 100.

Tabela 1 - Rendimentos dos sucos nas diferentes operações dos processos

\begin{tabular}{cccc}
\hline Operações & Pêra & Maçã & (Pêra/Maçã) \\
\hline OEX1 & 49,08 & 66,87 & 0,73 \\
OEX2 & 76,24 & 73,56 & 1,04 \\
OEX3 & 62,30 & 70,00 & 0,89 \\
OEX4 & 71,50 & 69,57 & 1,04 \\
\hline
\end{tabular}

Nota: (OEX1) Operação de Extração 1 - Tecnologia Mecânica; (OEX2) Operação de Extração 2 - Despolpadeira; (OEX3) Operação de Extração 3 Multiprocessador de Alimentos; (OEX4) Operação de Extração 4 - Tecnologia Enzimática.

\section{Qualidade do produto}

Os resultados das análises químicas para determinação da qualidade do suco de pêra e de maçã em função das operações de extração são apresentados na Tabela 2.

Os sólidos solúveis totais compreendem como compostos majoritários os açúcares simples, os ácidos orgânicos e os compostos fenólicos em escalas de 10\%, de 1,0\% e 0,1\%, respectivamente (WILL et al., 2000). O valor médio encontrado para o suco de pêra foi de $11,72^{\circ}$ Brix sem nenhum valor inferior ao mínimo legal. Para a pêra, especificamente, praticando os mesmos limites que os da maçã, se constatam que ocorre o mesmo caso, com o valor médio de $10,81^{\circ}$ Brix e sem amostras inferiores a $10^{\circ}$ Brix. Segundo a mesma legislação é possível adicionar até atingir o patamar de $30 \%$ de suco de pêra em suco de maçã, o que já sugere uma semelhança de composição centesimal entre as duas pomáceas, confirmada por Schobinger et al. (1995). Segundo os valores divulgados por Herrmann (2001) ambas apresentam valores muito próximos entre si o que comprova as suas razões relativas (pêra/maçã) nos quesitos densidade relativa $(0,999)$ e sólidos solúveis totais $(0,996)$.

Nesta fração, medida instrumentalmente, os principais componentes são os açúcares livres, ou simples, compreendendo o dissacarídeo sacarose e os monossacarídeos glucose e frutose, cuja concentração depende do grau de maturação. O teor de sacarose em pêra varia de zero a $15 \mathrm{~g}^{100 \mathrm{~g}^{-1}}$ enquanto a razão de glucose por frutose de 0,3 a 0,5 e na maçã, de 5 a 30 g. $100 \mathrm{~g}^{-1}$ de sacarose e a razão de glucose e frutose igual a da pêra de 0,3 a 0,5 g.100 $\mathrm{g}^{-1}$ (HERRMANN, 2001).

Dentre os componentes sólidos solúveis, os teores de ácido málico alcançam valores mais elevados do que a acidez total titulável, expressa em ácido tartárico. Se este fato não ocorrer significa que foi adicionado ao suco algum outro tipo de ácido ou houve uma decomposição 
biológica (SCHOBINGER et al, 1995). Os valores de ácido málico em suco de pêra divulgados por Herrmann (2001) compreendem a média, expressa em ácido málico, de $170 \mathrm{mg} .100 \mathrm{~g}^{-1}$ variando de 100 a $240 \mathrm{mg} .100 \mathrm{~g}^{-1}$ além de ácido cítrico, cuja média é de $140 \mathrm{mg} .100 \mathrm{~g}^{-1}$ variando de 80 a 200 mg. $100 \mathrm{~g}^{-1}$, Para a maçã, os valores de ácido málico apresentam a média de $426 \mathrm{mg} .100 \mathrm{~g}^{-1}$ variando $^{-1}$ de 270 a 790 em mg. $100 \mathrm{~g}^{-1}$ mais até $29,3 \mathrm{mg} .100 \mathrm{mg}^{-1}$ de ácido cítrico, ou seja, um valor relativo de 6\% apenas. Estes números mostram a relação malato: citrato que pode variar de 1,21:1 (pêra, relativamente mais cítrica) até 14:1 (maçã, mais málica). Assim, pode ser aceita a classificação de maçã como fruta doce e pêra, semi-ácida, uma vez que a segunda, na realidade, apresenta um ácido mais forte chegando mesmo a ser pungente. A acidez total titulável e calculada que foi determinada enquanto ácido málico indicou valores cuja média foi de $0,19 \pm 0,01 \mathrm{~g} .100 \mathrm{~mL}^{-1}$ para o suco de pêra com valores variando de 0,16 a 0,20 g. $100 \mathrm{~mL}^{-1}$, para o suco de maçã os valores médios foram de $0,35 \pm 0,01$ g. $100 \mathrm{~mL}^{-1}$ variando entre 0,33 a 0,39 g. $100 \mathrm{~mL}^{-1}$.

Os compostos fenólicos totais representam compostos minoritários em tecnologia de alimentos, mas ocupa um espaço amplo em tecnologia de sucos, principalmente nos obtidos de matérias primas com polpa. Participam de reações de escurecimento com a atividade enzimática inicial da polifenoloxidase transformando fenóis em quinonas que se polimerizam formando compostos coloridos de estrutura ainda incerta (OSZMIANSKI e WOJDYLO, 2006). No processamento de suco de maçã primeiro ocorre o gradativo escurecimento das arestas das frutas cortadas e toda a área comprometida com o processo fica impregnada com pigmentação polifenólica. Os compostos fenólicos, polimerizados ou não, se distribuem na etapa de separação do suco e do bagaço com uma afinidade estrutural de ligação com este último, tornando-o escuro e de má aparência enquanto o suco fica clarificado e límpido, ou mesmo com brilho, se for tratado com gelatina para extrair por colagem as partículas de proteínas e compostos fenólicos.

Os resultados de cada teste devem ser analisados caso a caso e é possível observar que existe uma coerência do perfil de compostos fenólicos variando de forma similar nos testes com peras, valores sempre mais baixos do que a maçã. Os teores médios de compostos fenólicos totais dos dois conjuntos foram muito próximos (com $8 \%$ de diferença) sugerindo a homogeneidade das frutas num aspecto geral, porém houve uma tendência de números mais baixos para a pêra e um comportamento oposto de conteúdos: na OEX2 e OEX4 são mais altos e nas demais são mais baixos enquanto que no caso da maçã as OEX1 e OEX4 são mais elevados. Com diferença estatística significativa os valores foram mais elevados para a maçã na OEX1 com valor de $362,27 \pm 2,37 \mathrm{mg} . \mathrm{L}^{-1}$ e para a pêra na OEX2 o valor de $283,20 \pm 24,09 \mathrm{mg} . \mathrm{L}^{-1}$.

Pelos motivos de serem benéficos pela eliminação dos radicais oxigênio reativo a maçã tem sido apontada como uma das frutas mais interessantes em termos de dieta, além de outras como a manga, açaí e mirtilo (CANCALON, 2007). Neste trabalho, com dados numéricos pode ser 
confirmado que as operações de processamento de suco de pêra e de maçã foram significativamente diferentes, mostrando valores mais elevados como $1413,33 \mu \mathrm{M} \cdot \mathrm{mL}^{-1}$ (OEX2 pêra) e como 1168,89 $\mu \mathrm{M} \cdot \mathrm{mL}^{-1}$ (OEX3 maçã).

A influência da OEX2 se manifesta pela intensidade de cor mais elevada em função da aeração que contribui com escurecimento dos polifenóis de ambas as frutas, atingindo valores de 5,12 e de 6,56 para a pêra e a maçã, respectivamente. O efeito da OEX1 nos dois casos levou a intensidade de cores mais próximas, como 3,95 e 3,81, enquanto a OEX3 apresentou para a pêra um valor de 5,29 e para a maçã 2,02. Exceto para esse caso, todos os demais se apresentaram homogêneos em relação às 3 leituras.

Tabela 2 - Características da qualidade dos sucos de pêra e maçã obtidos por diferentes operações de extração

\begin{tabular}{|c|c|c|c|c|c|}
\hline & SST $\left({ }^{\circ} \text { Brix }\right)^{*}$ & MAL $(\mathrm{g} / 100 \mathrm{~mL})^{*}$ & CFT (mg/L) & $\mathrm{CAO}(\mu \mathrm{M} / \mathrm{mL})$ & IC* \\
\hline \multicolumn{6}{|c|}{ Suco de Pêra } \\
\hline OEX1 & 10,50 & $0,20 \pm 0,01$ & $191,2^{c} \pm 19,63$ & $986,67^{\mathrm{de}} \pm 26,67$ & 3,95 \\
\hline OEX2 & 11,50 & $0,16 \pm 0,01$ & $283,20^{\mathbf{b}} \pm 24,09$ & $1413,33^{\mathbf{b}} \pm 17,78$ & 5,12 \\
\hline OEX3 & 11,25 & $0,20 \pm 0,01$ & $270,80^{\mathbf{b}} \pm 9,08$ & $1044,44^{\text {cd }} \pm 128,89$ & 5,29 \\
\hline OEX4 & 10,00 & n.d. & $279,39^{\mathbf{b}} \pm 31,81$ & $2954,80^{\mathrm{a}} \pm 325,00$ & 0,44 \\
\hline \multicolumn{6}{|c|}{ Suco de Maçã } \\
\hline OEX1 & 12,00 & $0,39 \pm 0,01$ & $362,27^{\mathrm{a}} \pm 2,37$ & $840,00^{\mathbf{e}} \pm 4,44$ & 3,81 \\
\hline OEX2 & 12,50 & $0,33 \pm 0,01$ & $299,74^{\mathbf{b}} \pm 23,83$ & $484,44^{\mathrm{f}} \pm 31,11$ & 6,56 \\
\hline OEX3 & 11,50 & $0,33 \pm 0,01$ & $218,09^{c} \pm 3,58$ & $1168,89^{\mathbf{c}} \pm 22,22$ & 2,02 \\
\hline OEX4 & 10,88 & n.d. & $322,58^{\mathbf{b}} \pm 29,17$ & $1627,91^{\mathbf{b}} \pm 222,61$ & 0,49 \\
\hline
\end{tabular}

Nota: (OEX1) Operação de Extração 1 - Tecnologia Mecânica; (OEX2) Operação de Extração 2 - Despolpadeira; (OEX3) Operação de Extração 3 Multiprocessador de Alimentos; (OEX4) Operação de Extração 4 - Tecnologia Enzimática. SST: sólidos solúveis totais; MAL: ácido málico; CFT: compostos fenólicos totais; CAO: capacidade antioxidante; IC: índice de cor. Valores representados pela mesma letra não apresentam diferença significativa $(\mathrm{p}<0,05)$ * Não apresentam análise de variância.

\section{Conclusão}

O rendimento gravimétrico de suco de pêra médio apontou para um valor menor do que para a maçã com uma diferença de 5,22\%, caracterizando as duas matérias-primas aptas aos procedimentos tecnológicos apropriados comprovando a validade de processamento da nova matéria prima com os velhos processamentos. A razão entre os rendimentos da pêra pelos da maçã indicam a mesma aptidão tecnológica se forem focalizados as operações OEX2 e OEX4 na preparação do mosto, enquanto que nos procedimentos OEX1 e OEX3 os rendimentos maiores foram observados para a maçã.

\section{Agradecimentos}

À Universidade Estadual de Ponta Grossa, que adotou o apoio aos grupos emergentes de pesquisa permitindo o uso de sua infra-estrutura científica por acadêmicos, alunos ou professores, mesmo de outras instituições para o desenvolvimento do aprendizado pelas atividades de pesquisa. 
Ao CNPq e à CAPES, que sempre confiou na qualidade das iniciativas da junção do ensino e da pesquisa concedendo auxilio financeiro sob a forma de taxas de bancadas e /ou de bolsas desde iniciação científica até as de pós-doutorado.

\begin{abstract}
Pear cultivation shows a high growth potential because there are an apple culture already installed that modified recently the economy and attitudes of the people involved. The Country, considered part of the BRICS (Brazil, Russia, India, China and South Africa), the largest fruit producer may in a short time to supply the market with high competitive pears. The main objective of this article deals with the evaluation of the possibility to utilize part of such infrastructure to implantation and storage of the culture of pear, including since the genetic improvement by modern and actualized research up to critical management techniques, reaching more actualized and safe products. So, it would be possible to utilize the known technological routes of the apple to that of pear aiming to produce noble products within a short period time. Industrial units involved with pear juice processing are quite seldom although the high production crops with a high production tend to stabilize the internal marked. In this sense some samples of commercial pears are reported concerning to the singularities since botanical aspects up to fining of the fruit juice keeping apple as scientific and technologic reference. The adequacy of pear to the equipment must be high in order to rapid convert one for another. The gravimetric yield compared from pear and apple juice were interesting in order to point out the affinity of each raw material although results obtained with depulper and for enzyme technology were both more interesting.
\end{abstract}

Key-words: pomaceas, processing operations, products.

\title{
Referências
}

BENZIE, I. F. F.; STRAIN, J. J. The ferric reducing ability of plasma (FRAP) as a measure of "antioxidant power": the FRAP assay. Analytical Biochemistry, v. 239, n. 1, p. 70-76, 1996. http://dx.doi.org/10.1006/abio.1996.0292

BINNING, R.; POSSMANN, P. Apple juice. In: NAGY, S.; CHEN, C. S..; SHAW, P. E. Fruit Juice Processing Technology. Agscience, 1993.

BIRUS, T. Moderne Apfelsaft-Technologie: Das Fruchtsaft-Fachbuch für den Pratiker aus der Fachbuchserie des Fachverlages. Früssiges Obst GmbH, 2001.

CANCALON, P. F. The "in vitro" chemical estimation of fruit-juice antioxidant potentials may not reflect the "in vivo" benefical effects of phytochemicals. Fruit Processing, v. 17, n. 2, p. 74-79, 2007.

CLAUDINO, H. As 50 frutas e seus benefícios medicinais. São Paulo: Editora Elevação Ltda., 2009.

DEELEN, W. V.; STEINBUCH, E. Zur enzymatischen Saftgewnnung von Gemüsen und Früchten. Confructa Studien, v. 30, n. 1, p. 15-23, 1986.

FERTONANI, H. C. R.; SIMOES, D. R. S.; NOGUEIRA, A.; WOSIACKI, G. Potencial da variedade Joaquina para o processamento de suco clarificado e vinho seco de maçã. Ciência e Tecnologia de Alimentos, v. 26, n. 2, p. 434-440, 2006. http://dx.doi.org/10.1590/S0101-20612006000200029

FIORAVANÇO, J. C. A cultura da pereira no Brasil. Situação econômica e entraves para seu crescimento. Informações Econômicas, v.37, n.3, p 52-59, 2007.

HAMINIUK, C. W. I.; OLIVEIRA, C. R. G.; BAGGIO, E. C. R.; MASSON, M. L. Efeito de pré-tratamento no escurecimento das cultivares de maçã Fuji e gala após o congelamento. Ciência e Agrotecnologia, v. 29, n. 5, p. 10291033, 2005. http://dx.doi.org/10.1590/S1413-70542005000500017 
HERRMANN, K. Inhaltsstoffe Von Obst und Gemüse. Eugen Ulmer GmbH, 2001.

HURLEY, A.; WEY, R. Technik des Mahlens und Maischens. Confructa Studien, v. 28, n. 2, p. 125-131, 1984.

IAL. Métodos físicos e químicos para análise de alimentos. Normas Analíticas. São Paulo: Instituto Adolfo Lutz, 2005 .

ISSENHUT, F.; SCHNEIDER, I. The new generation of panzym mash. Fruit Processing, v. 18, n. 5, p. 254-256, 2008.

MAIER, G. Enzymes - Flexible tools to improve process efficiencies in order to optimize raw material usage and support the development of new beverage. Fruit Processing, v. 20, n. 6, p. 242-246, 2010.

NIKETIC-ALEKSIC, G.; SLATKOVIC, B.; BUKVIX, B.; JANDA, L. Die Wirkung verschiedener Birnensorte und eines modifizierten, technologischen verfahrens auf die Qualität von Birnensaft. Flüssiges Obst, v. 58, n. 2, p. 55-60, 1989.

NOGUEIRA, A.; MONGRUEL, C.; OLIVEIRA, M. C. S. de; PASSOS, M.; WOSIACKI, G. Avaliação da trituração e de tratamentos enzimáticos na obtenção de suco de maçã por centrifugação. Publicatio UEPG Ciências Exatas Terra, Ciências Agrárias e Engenharia, v. 11, p. 7-12, 2005.

NOGUEIRA, A.; SANTOS, L. D.; WIECHETECK, F. V. B.; GUYOT, S.; WOSIACKI, G. Efeito do processamento no teor de compostos fenólicos em suco de maçã. Publicatio UEPG Ciências Exatas e da Terra, Ciências Agrárias e Engenharias, v. 9, n. 3, p. 7-14, 2003.

OSZMIANSKI, J.; WOJDYLO, A. Effect of pectolytic enzyme preparations on the phenolic composition and antioxidant activity of apple juice. Fruit Processing, v. 6, n. 5, p. 322-329, 2006.

PULIDO, R.; BRAVO, L.; SAURA-CALISTO, F. Antioxidant activity of dietary polyphenols as determined by a modified ferric reducing/antioxidant power assay. Journal of Agricultural and Food Chemistry, v. 48, n. 8, p. 33963402, 2000. http://dx.doi.org/10.1021/jf9913458

SAWAZAKI, H. E.; BARBOSA, W.; COLOMBO, C. A. Caracterização e identificação de cultivares e seleções de pereiras através de marcadores RADP. Revista Brasileira Fruticultura de Jaboticabal, v. 24, n. 2, p. 447-452, 2008. http://dx.doi.org/10.1590/S0100-29452002000200033

SCHOBINGER, U.; BARBIC, I.; DÜRR, P.; WALDVOGEL, R. Phenolic compounds in apple juice - positive and negative effects. Fruit Processing, v. 6, p. 171-178, 1995.

SINGLETON, V.; ROSSI, J. A. Colorimetry of totals phenolics with phosphomolybdicphosphotungstic acid reagents. American Journal of Enology and Viticulture, v. 16, n. 3, p. 144-158, 1965.

STUTZ, C. Enzymatische Verfüssigung: Vision oder Tatsache? Flüssiges Obst, v. 62, n. 7, p. 371-373, 1996.

TANNER, H.; BRUNNER, H. R. Getränke Analytic: Untersuchungsmethoden für die Labor und Betriebspraxis. Wädenswill: Helles, 1985.

WILL, F.; BAUCKHAGE, K.; DIETRICH, H. Apple pomace liquefaction with pectinases and cellulases: analytical data of the corresponding juices. European Food Research and Technology, v. 211, p. 291-297, 2000. http://dx.doi.org/10.1007/s002170000171

Submetido em 15 set. 2011; Revisão submetida pelos autores em 15 out 2011, Aceito para publicação em 29 dez 2011. 